\title{
El derecho cooperativo nicaragüense como instrumento de desarrollo social ${ }^{1}$
}

Nicaraguan cooperative law as an instrument of social development

\author{
William Tórrez Peralta² \\ Universidad Centroamericana, Managua (Nicaragua)
}

Sumario: Introducción. 1. Antecedentes históricos del Derecho cooperativo en Nicaragua. 1.1. El cooperativismo de 1914 a 1979. 1.2. El cooperativismo de 1979 a 2020. 2. El rol de las cooperativas en la gestión del medio ambiente. 2.1. La protección estatal al medio ambiente. 2.2. El cuido del medio ambiente por las cooperativas. 3. Las cooperativas y la exclusión social. 3.1. La exclusión social en Nicaragua. 3.2. La exclusión social en las cooperativas. 4. Las cooperativas y la protección social de sus socios. 4.1. Nociones generales de la Seguridad Social en Nicaragua. 4.2. El régimen de Seguridad Social en las cooperativas. 5. Conclusiones. 6. Bibliografía.

Summary: Introduction. 1. Historical antecedents of cooperative law in Nicaragua. 1.1. Cooperativism from 1914 to 1979. 1.2. Cooperativism from 1979 to 2020. 2. The role of cooperatives in environmental management. 2.1. State protection of the environment. 2.2. Caring for the environment by cooperatives. 3. Cooperatives and social exclusion. 3.1. Social exclusion in Nicaragua. 3.2. Social exclusion in cooperatives. 4. Cooperatives and the social protection of their members. 4.1. General notions of Social Security in Nicaragua. 4.2. The Social Security regime in cooperatives. 5. Conclusions. 6. Bibliography.

1 Este trabajo es fruto de la estancia internacional realizada en la Universidad de Deusto y, más concretamente, en el grupo de investigación reconocido por el Gobierno Vasco «Cooperativismo, fiscalidad, fomento, relaciones laborales y protección social» (IT 1089-16), bajo la dirección de Francisco Javier Arrieta Idiakez, investigador principal de dicho grupo y profesor titular de Derecho del Trabajo y de la Seguridad Social de la Facultad de Derecho de la mencionada universidad, del 6 de noviembre del 2019 al 20 de diciembre de 2019, en virtud de la financiación recibida en el marco del Contrato Programa UD-Programa de apoyo a Equipos de Investigación trienio (2019-2021), para el programa 7: acciones especiales y de transferencia e impacto social.

2 Profesor de Derecho procesal. Email: wtperalta@gmail.com. 
Resumen: El cooperativismo en Nicaragua ha sido, es y será, a medio y largo plazo, un factor clave de desarrollo socio-económico. A pesar de los diferentes regímenes políticos, el cooperativismo no sólo se ha mantenido, sino que se ha desarrollado y consolidado, convirtiéndose en la actualidad en una pieza clave dentro de la estructura económica del país. No obstante, la riqueza de esta figura desde un análisis filosófico y conceptual permite extender y superar su hasta entonces reducida concepción economicista y traspolarla a otras áreas sociales. Si los problemas actuales exigen nuevas respuestas, las soluciones pueden venir de la actualización de figuras ya existentes. Esta cuestión es la que atraviesa este breve ensayo, articulando la realidad del cooperativismo y el papel que juega como impulsor de desarrollo en otras áreas, tales como el medio ambiente, la exclusión social y la Seguridad Social.

Palabras claves: Derecho cooperativo, medio ambiente, Seguridad Social, Nicaragua.

Abstract: Corporativism in Nicaragua has been, is and will be, in the medium and long term, a key factor in socio-economic development. Despite the different political regimes, cooperativism has not only been maintained, but has developed and consolidated, becoming today a key part of the country's economic structure. However, the wealth of this figure from a philosophical and conceptual analysis allows to extend and overcome its hither to reduced economic conception and to transfer it to other social areas. If current problems call for new answers, solutions may come from updating existing figures. This question is the one that this short essay goes through, articulating the reality of cooperativism and the role it plays as a driver of development in other areas, such as the environment, social exclusion and Social Security.

Keywords: Cooperative Law, environment, social security, Nicaragua. 


\section{Introducción}

Como nicaragüense interesado en los asuntos sociales de mi país, he estado siempre cerca de las realidades tan distintas por las que ha atravesado este estado centroamericano, siempre intentando conocerlo mejor, para entenderlo y, con toda humildad, explicarlo. En este caso, la Universidad de Deusto me ha brindado la oportunidad de exponer en este breve artículo una realidad muy significativa en los países Latinoamericanos y que, en el caso de Nicaragua, se vinculó su auge al contexto revolucionario ocurrido en la década de los ochentas del siglo pasado, impronta que a pesar de los cambios, se ha mantenido y expandido lo que permite afirmar que el cooperativismo en Nicaragua responde a realidades que van más allá de lo político y que se presenta como una respuesta actual a problemas y necesidades vigentes.

En Nicaragua la figura del cooperativismo se comprende desde la visión tradicional de su capacidad para integrar al excluido en el mercado, es decir, de la inserción del trabajador en el orden de gestión de su propio trabajo y disfrute de sus frutos. De ahí que se enmarque dentro de una ideología antiliberal. No obstante, en la actualidad, diversas cooperativas están reflejando un cambio en este sentido, encontrándonos con cooperativas conformadas por sectores medios (ejemplo, el transporte, la caficultura, la ganadería, entre otros).

Entender el cooperativismo en Nicaragua y evaluar su incidencia en el presente nos permitirá proyectar sus enormes posibilidades en el futuro como mecanismo de impulsión económica en general y como instrumento de reducción de la exclusión social, en particular. Es por ello que el análisis que procedemos a exponer, aunque breve, pretende incorporar lo que entendemos humildemente, son elementos clave para entender y valorar el cooperativismo nicaragüense.

El artículo comienza con una sucinta exposición de los antecedentes históricos distinguiendo por etapas marcadas por las drásticas diferencias de régimen político hasta la actualidad. Tras este análisis histórico, se presentará el cooperativismo desde tres ejes fundamentales: el papel del cooperativismo como instrumento de protección al medio ambiente, su papel ante la exclusión social y la incorporación de sus socios al sistema de Seguridad Social. La elección de estos tres ejes, entre otros muchos sobre los que se podría disertar en esta materia tan amplia, se justifica por la coincidencia entre acción del cooperativismo y su directa incidencia en los ejes señalados, que configuran a su vez tres de los problemas más graves por los que atraviesa Nicaragua: deterioro grave de su medio ambiente, exclusión social (en la forma en la cual se analizará) y una elevadísima tasa de población fuera de la Seguridad 
Social. Debe observarse que estos ejes se interrelacionan entre sí en un esquema de causa-consecuencia.

Se cierra el artículo con unas conclusiones y propuestas que pretenden ser la antesala para futuros trabajos de investigación, pero sobre todo sirvan como elementos para el debate al servicio de un desarrollo del cooperativismo más eficiente y solidario.

\section{Antecedentes históricos del Derecho cooperativo en Nicaragua}

Para hablar del Derecho cooperativo nicaragüense, hay que remitirse a la historia de su legislación, referente a las primeras disposiciones y al desarrollo teórico y legal de estas, pues estos referentes nos dan la pauta de su evolución y significado. Por otro lado, el Derecho cooperativo atiende en gran manera a la misma historia del país, debiendo dirigirse su estudio dentro del marco del contexto histórico del país donde actúa.

En Nicaragua como en el resto de los países de América Latina, el origen del cooperativismo influenciado por corrientes europeas respondió a modelos específicos de propuestas de organización social y gestión económica. La Iglesia católica, los movimientos sindicales y los partidos políticos también han participado en la evolución del cooperativismo como factores de impulsión.

\subsection{El cooperativismo de 1914 a 1979}

Las cooperativas en Nicaragua fueron establecidas por primera vez en el Código de Comercio de $1914^{3}$. Se dedicaba este cuerpo de leyes en su Capítulo VII, del artículo 300 a 328, a las Sociedades Cooperativas. El artículo 300 del citado Código decía que «las sociedades cooperativas se caracterizan por la variabilidad del capital social, ilimitación del número de socios, y el objeto de ellas, que es por lo regular, el ahorro sobre gastos de consumo, la concesión del crédito reciproco, el ejercicio de una industria, la construcción de habitaciones, o la participación de utilidades entre capitalistas y operarlos».

Al promulgarse el Código de Comercio no existía aún en Nicaragua ninguna cooperativa organizada (la primera no se constituyó hasta

3 Ley s/n, de 30 de abril de 1914 (La Gaceta Diario Oficial n. ${ }^{\circ} 248$ de 30 de octubre de 1916). 
1926). Lo que existía en Nicaragua hasta antes de 1926 eran agrupaciones de trabajadores en la ciudad como resistencia pacífica ante las condiciones laborales impuestas en las fábricas, con características reivindicatorias para defender sus derechos laborales.

Luego de la promulgación del señalado Código se dan algunos intentos de formar cooperativas bajo expresiones asistencialistas de ayuda mutua con el propósito de enfrentar situaciones de pobreza a partir de la creación de un fondo social. No fue sino hasta años posteriores que se dan verdaderos intentos de un cooperativismo más consolidado.

Fue en el año 1926 cuando se genera un auténtico movimiento cooperativo nicaragüense, el cual nace de la mano de Augusto C. Sandino ${ }^{4}$. Tras 1934, fecha que fija el ocaso de la gesta de Sandino, asume el poder Anastasio Somoza García, marcando una nueva etapa del cooperativismo el cual comienza a visualizarse como un elemento subversivo, al ligarse de manera directa a Sandino.

En 1944 empujado por la presión del movimiento obrero, el régimen de Somoza García se vio obligado a promulgar el primer Código del Trabajo ${ }^{5}$. Este Código incorpora el reconocimiento de las cooperativas como organizaciones legalmente constituidas, y así fueron generándose cooperativas de consumo en empresas que aglutinaban a muchos trabajadores, como la Portuaria del Occidente del país y el Ferrocarril del Pacífico. En estas cooperativas los trabajadores tuvieron que aportar dinero para su formación al margen de las aportaciones estatales. Este fue un modelo de ayuda mutua asistencialista sin carácter empresarial. Cuando se terminó el apoyo del Estado, desaparecieron, a finales de los años cincuenta. Téngase en cuenta la diferente conceptualización del cooperativismo desde un enfoque mercantilista (Código de Comercio de 1914) al sentido impreso desde un Código Laboral.

No fue hasta la década de los años sesenta, que el cooperativismo nicaragüense volvió a ser objeto de la atención del Estado, cuando el Gobierno de Estados Unidos impuso apresuradamente el programa de Alianza para el Progreso, en respuesta al impacto causado por la revolución cubana de 1959, sobre los movimientos sociales en América Latina. Este programa de ayuda económica, política y social cubrió casi

${ }^{4}$ Gómez Izaba, Erwin. 1979. «Apuntes sobre la historia del movimiento cooperativo en Nicaragua». Cooperativas en Centroamérica, Historia y Marco Jurídico, s/n: 213.

5 Ley $s / n$, de 23 de noviembre de 1944 (Diario Oficial La Gaceta n. ${ }^{\circ} 23$, de 1 de febrero de 1945). Este Código fue derogado por el Código del Trabajo, Ley 185/1996, de 5 de septiembre (La Gaceta Diario Oficial n. 205 de 30 de octubre de 1996). 
toda América Latina y el Caribe desde 1960 a principios de los años setenta6.

En el marco del Programa de Alianza para el Progreso, Nicaragua impulsa tres proyectos: a) un programa de reforma agraria; b) la cooperativización urbana, fundamentalmente, y c) proyectos agrícolas dirigidas a campesinos en zonas determinadas ${ }^{7}$. Bajo este contexto, en el año 1965 se crea en Nicaragua la primera Federación de Cooperativas de Ahorro y Crédito (FECACNIC) que era uno de los objetivos del programa de la Alianza para el Progreso.

Tras el terremoto de diciembre de 1972 que destruyó la ciudad de Managua, se da un nuevo auge del cooperativismo, pero esta vez en una forma diferente. Resurge el comercio y dentro del Programa norteamericano mencionado, aparece como ente promotor del cooperativismo una ONG Ilamada «Fundación para el Desarrollo» que organiza cooperativas de comerciantes en los mercados. En estos intentos se desarrollaron mecánicas de estilo empresarial con directivas integradas por presidentes y gerentes. En este nuevo concepto de cooperativismo de corte más mercantilista, el 23 de julio de 1971 se publica la Ley General de Cooperativas. No obstante, y como parte de las políticas propias de las dictaduras, esta Ley tuvo una marcada visión paternalista impulsada por el Estado y apoyada por la empresa privada. El 10 de marzo de 1975 se decreta el Reglamento de la Ley General de Cooperativas de 1971 .

Con todo lo anterior, podemos afirmar que el cooperativismo en $\mathrm{Ni}$ caragua como fenómeno socioeconómico antes de 1979 fue marginal.

6 La Alianza para el Progreso creada por el presidente John F. Kennedy en el año 1961, tenía como objetivo combatir la creciente pobreza y las grandes desigualdades sociales en latinoamericana para crear una clase media, mediante la asignación de un fondo de aproximadamente de $\mathbf{2 0 . 0 0 0}$ millones de dólares por diez años, que serían destinados a perfeccionar sus instituciones democráticas, acelerar su desarrollo económico y social, ejecutar programas de vivienda, impulsar la reforma agraria, asegurar una justa remuneración a los trabajadores, acabar con el analfabetismo, desarrollar programas de salubridad e higiene, reformar los impuestos en sentido progresivo y profundizar en la integración económica de América Latina, todo ello para prevenir la tentación revolucionaria, es decir, contener el comunismo en ese subcontinente. En este contexto se definido el rol que tendría la Organización de Estados Americanos (OEA), el Banco Interamericano de Desarrollo (BID) y la Comisión Económica para América Latina (CEPAL). Se definió asimismo el papel que la OEA, el BID y la CEPAL en la canalización de los fondos y la designación de los proyectos. También se previó la participación tanto de las inversiones privadas nacionales como de las fuentes de financiamiento provenientes de Europa y Japón.

7 Salom Echeverria, Alberto et al. 1992. El estado del cooperativismo en Nicaragua. San José: Alianza Cooperativa Internacional. 
En definitiva, el cooperativo en esta época no jugó un papel trascendental en la producción del país. No generó una movilización ni en el campo ni en la ciudad, ni fue tampoco importante por el número de asociados que alcanzó ni por el peso de la producción.

\subsection{El cooperativismo de 1979 a 2020}

Como consecuencia de una guerra civil sangrienta denominada «guerra de liberación nacional», cuando triunfa la revolución popular sandinista el 19 de julio de 1979, el gobierno revolucionario adoptó una serie medidas tendentes a instaurar un nuevo sistema político y jurídico, como elementos esenciales en la etapa de transición hacia un nuevo régimen ${ }^{8}$. En consideración a lo anterior, la Constitución política de Nicaragua de 1974 fue derogada. Como consecuencia de ello, el Gobierno de Reconstrucción Nacional promulgó el Estatuto Fundamental ${ }^{9}$, la nueva Norma Fundamental del país vigente hasta 1987.

El Estatuto Fundamental establecía «el derecho a fundar y promover cooperativas de trabajo y producción». En este sentido, el movimiento cooperativo tuvo gran empuje siendo especialmente de carácter agropecuario, ya que el Frente Sandinista de Liberación Nacional como vanguardia de la revolución adquirió un compromiso histórico de trasformar radicalmente las estructuras y las relaciones sociales en beneficio de los campesinos ${ }^{10}$. Este modelo formó parte de una estrategia del gobierno revolucionario que asumió un rol protagónico, canalizando el proceso de reforma agraria en formas cooperativas.

De este Estatuto Fundamental se derivaron las siguientes normas jurídicas esenciales para apoyar la propiedad cooperativa:

1) Decreto 3-38/1979 de 8 de agosto ${ }^{11}$, que contemplaba la confiscación de las tierras en manos de la familia Somoza y sus allegados a la dictadura para ser entregadas al Estado revolu-

8 Alemán, Estela, et al. 1992. Revolución, ajuste económico y el cooperativismo agrario en Nicaragua 1979-1991. Managua: Universidad Nacional Autónoma de Nicaragua.

9 Ley 52/1979, de 21 de agosto (La Gaceta Diario Oficial n. ${ }^{\circ} 11$ de 17 de septiembre de 1979).

10 Fitzgerald, Valpy y Chamorro, Amalia. 1987. "Las cooperativas en el proyecto de transición en Nicaragua». Encuentro, n. ${ }^{\circ}$ 30: 21. En el mismo sentido, Jarquín Chamorro, Mateo. et al. 2020. Anhelos de un Nuevo Horizonte. Aportes para una Nicaragua Democrática. San José: FLACSO de Costa Rica.

11 La Gaceta Diario Oficial n. ${ }^{\circ} 6$ de 3 de septiembre de 1979. 
cionario y este a la vez las entregara al campesinado pobre en forma de propiedad cooperativa. Con este Decreto se confisco el 20 por ciento de las tierras productivas en todo el país ${ }^{12}$.

2) Ley de Reforma Agraria de $1981^{13}$, que reconoció tres formas de propiedad: privada, cooperativa y estatal. Asimismo, con esta Ley se reconoce la propiedad comunal de los indígenas del Caribe nicaragüense. Proclamando en su Exposición de Motivos: "Que bajo el régimen somocista el desarrollo agropecuario favoreció únicamente a reducidos grupos privilegiados, sumiendo a los campesinos y obreros agrícolas en la miseria, el atraso y la ignorancia e impidiendo el aprovechamiento pleno de los recursos naturales del país. Que por lo tanto es de absoluta necesidad impulsar una transformación profunda de las estructuras agrarias heredadas del régimen anterior de tal manera que se establezcan las condiciones para avanzar hacia formas superiores de organización de la producción y se garantice a los campesinos y obreros agrícolas una constante superación material y cultural».

3) Ley de Cooperativas Agropecuarias de $1981^{14}$, que en su apartado V de la Exposición de Motivos decía que: «Ley General de Cooperativas» vigente en el país, emitida por el gobierno somocista en julio de 1971, no responde a las aspiraciones revolucionarias del campesino nicaragüense ni establece el marco adecuado para el desarrollo de un dinámico y pujante movimiento cooperativo como el que impulsa la Revolución Popular Sandinista en el sector agropecuario». Y el art. 2 de la señalada Ley proclamaba: "La cooperativa agropecuaria es una forma superior de organización del trabajo que impulsa el espíritu de solidaridad y cooperación superando las relaciones de competencia y explotación entre los hombres...».

4) Ley de Reforma a la Ley de Reforma Agraria de 11 de enero de 1986, sustituyó a la anterior Ley de $1981^{15}$. Esta reforma supone una extensión subjetiva de la Ley anterior la cual quedaba

12 Flores Rivas, María Hayde. 1988. La reforma agraria. León: Universitaria.

13 Decreto-Ley 782/1981 de 19 de julio (Diario Oficial La Gaceta n. ${ }^{\circ} 188$ de 21 de agosto de 1981). Esta Ley establecía la posibilidad de expropiar a cualquier propietario de tierras ociosas fijando un límite de 350 hectáreas en las regiones más productivas y de 700 en el resto del país. No tenía por objeto esta norma eliminar el latifundio.

14 Decreto-Ley 826/1981 de 17 de septiembre (Diario Oficial La Gaceta n. ${ }^{\circ} 222$ de 2 de octubre de 1981).

15 Ley 14/1986 de 11 de enero (Diario Oficial La Gaceta n. 8 de 13 de enero de 1986).

Boletín de la Asociación Internacional de Derecho Cooperativo 
circunscrita a la familia y allegados de Somoza. Esta nueva Ley se extenderá a cualquier propiedad ociosa, o insuficientemente explotada ${ }^{16}$, otorgándole atribuciones al Estado para afectarlas sin excepción.

En 1987 se aprobó la Constitución política de Nicaragua que derogó al Estatuto Fundamental de la República. Esta nueva Norma Fundamental establece el fomento y la creación de cooperativas, disponiendo al Estado a favor de su creación y apoyo a las mismas.

El cooperativismo nicaragüense obtiene así una norma de rango constitucional a través del artículo 109 que proclama: «El Estado promoverá la asociación voluntaria de los campesinos en cooperativas agrícolas, sin discriminación de sexo y de acuerdo con sus recursos facilitará los medios materiales necesarios para elevar su capacidad técnica y productiva, a fin de mejorar las condiciones de vida de los campesinos». No obstante, recordemos que, de manera paralela, se está aplicando la Ley de Reforma Agraria de 1986 la cual impone el cooperativismo a aquellos productores beneficiados por el reparto de la tierra auspiciada por el Estado. En estas condiciones, la tenencia de la tierra en Nicaragua se modificó radicalmente, hasta el extremo que el sector privado tradicional, descendió del cien por cien al $45 \%$ de la tierra ${ }^{17}$.

Entre los años 1985 a 1989 se profundiza la crisis económica y por ende el modelo de gobierno existente. La guerra de «agresión» y el

16 Para enfrentar esta situación de crisis de la reforma agraria se decidió reformar la ley. Las reformas decretadas en enero de 1986, por primera vez deciden enfrentarse al latifundio. Se suspenden las limitaciones de 700 hectáreas en las regiones al este del país y 350 en la zona del Pacífico, y se establece que pueden ser sancionadas las tierras ociosas, abandonadas o mal explotadas por sus dueños, independiente del área que posean. A las tierras eficientemente explotadas se les garantiza la propiedad, pero se da a la ley el derecho de afectar el derecho de la indemnización. estas propiedades en casos puntuales, mediante la facultad de expropiar por causas de utilidad pública o interés social. Además, se sanciona la ociosidad en los mismos términos del abandono, quitándole el derecho de la indemnización. Las reformas a la Ley han puesto en discusión las posibilidades de la existencia de la economía mixta. En este nuevo texto la Ley permite afectar cualquier propiedad, incluso las que están siendo eficientemente trabajadas, a pesar de que se garantiza en la ley este tipo de propiedad. En el pasado reciente, cuando no existía una voluntad decidida de liquidar el latifundio, muchas propiedades fueron afectadas aun cuando eran eficientemente explotadas. Los argumentos fueron varios, algunos provocados por una presión campesina que incidía encima de esa propiedad y generaba crisis, y en otros casos se procedió contra propietarios que habían optado por colaborar con la agresión norteamericana.

17 (Salom Echeverría, 1992, 15-16). 
bloqueo económico y comercial de Estados Unidos, por un lado, están dejando pérdidas enormes al aparato productivo; por otro lado, se produjo la reducción de suministros del campo socialista provenientes de Europa del Este, como consecuencia de las reformas instauradas por el dirigente soviético MIJAÍl GORBACHOV denominadas «perestroika» y «glasnost» ${ }^{18}$. Todo ello, obligó al gobierno sandinista a negociar con las fuerzas opositoras llamadas "contrarrevolucionarias» unos acuerdos de paz y estabilidad lo que conllevó a elecciones generales el 25 de febrero de 1990, en el cual el Frente Sandinista de Liberación Nacional fue desplazado del poder.

De esta época revolucionaria podemos decir que el cooperativismo, se consolidó - a pesar de todos problemas que se dieron- como base de apoyo social revolucionario con el que contó la revolución sandinista a lo largo de los años 80.

A partir del año 1990, tras la derrota electoral del gobierno sandinista se producen cambios en el orden político, económico y social que significaron para el cooperativismo nicaragüense un periodo de transformaciones radicales.

Estos cambios acelerados, obligaron al cooperativismo a buscar mecanismos concretos para desenvolverse ante las nuevas realidades. En esta búsqueda se fundó la Federación Nacional de Cooperativas Agropecuarias y Agroindustriales. Así se promulgó la Ley de Cooperativas Agropecuarias y Agroindustriales el 24 de marzo de 1990, la cual derogó la Ley de Cooperativas del periodo revolucionario. Que en sus apartados II y III de la Exposición de Motivos proclamaba que: «El Estado garantiza la propiedad cooperativa y la libre asociación voluntaria

18 Luis Carrión Cruz, uno de los máximos dirigente de la revolución y Ministro de Economía, manifestó: "La economía nicaragüense se encuentra en un estado crítico, sin ninguna reserva de divisas, con una infraestructura productiva (puertos y carreteras) al borde de la destrucción total, un estancamiento de los créditos, tanto de países occidentales como socialistas, y sin perspectivas de solución para la sangría que ocasiona la guerra. Como consecuencia, "el país pasa hambre"». Sigue añadiendo el dirigente sandinista que: "Esto no quiere decir que todo lo que hayamos hecho nosotros haya estado bien hecho. Hemos cometido errores. Por ejemplo, no siempre seguimos una política que estimulara la producción agropecuaria». Entre guerra y errores, lo cierto, según reconoce el comandante Carrión, es que "el deterioro que se ha acumulado es muy grande». "Hemos acumulado», explica, "una tremenda carencia de todo el sistema productivo; no tenemos disponibilidad de divisas, nuestra reserva de divisas es cero, es decir, estamos siempre por debajo, estamos dependiendo de la venta por adelantado de nuestras cosechas». Carrión Cruz, Luis. 1988. "Nicaragua pasa hambre» El País, 13 de noviembre. Acceso el 24 de nombre de 2019. https://elpais.com/ diario/1988/11/01/internacional/594342012_850215.html 
de los campesinos en cooperativas agrícolas, sin discriminación de ningún tipo, como una alternativa eficaz para el desarrollo económico del país. Que la autonomía de las cooperativas es indispensable para su desarrollo y libre desenvolvimiento, de acuerdo a los principios cooperativos universales, por lo que se hace necesario fortalecer su integración a través de formas superiores de organización». Como puede observarse, recuerda en su esencia al concepto cooperativista de la Constitución de Nicaragua de 1987.

Esta Ley de 1990 fue la base de la actual Ley General de Cooperativas, Ley 499/2004, de 29 de septiembre, publicada en La Gaceta n. 17 de 25 de enero de 2005, y complementada por su Reglamento aprobado el 10 de septiembre del 2007, publicado en La Gaceta n. ${ }^{\circ} 174$ de 11 de septiembre de 2007.

La Ley General de Cooperativas (en adelante LGC) crea el Instituto Nicaragüense de Fomento Cooperativo (INFOCOOP), esta entidad se establece con una personalidad jurídica propia, con autonomía administrativa y funcional. Se trata del organismo rector de la política nacional nicaragüense para lo relacionado a la protección, fomento y desarrollo cooperativo. Además, se encarga de la regulación, suspensión, supervisión y control de las cooperativas. Dentro de sus objetivos principales se encuentran fomentar, promover, divulgar y apoyar el movimiento cooperativo existente en Nicaragua. Asimismo, la misión del INFOCOOP es ser el Instituto autónomo del Estado nicaragüense, rector y gestor de las políticas públicas nacionales para la protección, fomento y desarrollo del movimiento cooperativo, como modelo de transformación para el bienestar de las familias nicaragüenses.

El INFOCOOP cuenta con una serie de atribuciones y funciones (arts. 114 y ss. LGC), entre las que destacan la promoción y ejecución de políticas, fomentar el cooperativismo, autorizar y certificar la constitución de las cooperativas en Nicaragua, velar por el cumplimiento de las disposiciones legales por parte de las cooperativas, censar informaciones relacionadas con el sector, investigar en el tema cooperativo en Nicaragua, así como todas aquellas acciones que se ejecuten a favor de las empresas de la economía social en Nicaragua, especialmente en las cooperativas.

La misma LGC en sus artículos 126 y ss., creo el Consejo Nacional de Cooperativas (CONACOOP), como un organismo conformado por los delegados del sector cooperativo electos en asamblea departamentales, regionales y nacionales que conforman la Asamblea Nacional de Cooperativas, quienes eligen a diez representantes del movimiento, que conforman la junta directiva, teniendo dentro de sus objetivos el definir políticas públicas para el sector. 
EI CONACOOP es el órgano rector del movimiento cooperativo nicaragüense, cuya finalidad responde a la representación y defensa del sector, consecuentemente es un órgano político por lo que debe de dictar los grandes lineamientos por lo que se debe regir el cooperativismo nacional. Tiene como misión y objetivo, beneficiar a todos los cooperados, impulsando el desarrollo económico y social de los cinco ejes del movimiento cooperativo existentes en el país.

De lo anteriormente expuesto, podemos decir que con sus altos y bajos actualmente el movimiento cooperativo nicaragüense ha manifestado un desempeño que tiende a su consolidación como opción real de desarrollo a nivel nacional. Nicaragua se ha convertido en el país con el mayor número de cooperativas de Centroamérica. A falta de un censo cooperativo citamos las declaraciones del Gerente general de la Cooperativa de Ahorro y Crédito Caja Rural Nacional, quien señala que en el año 2007 Nicaragua tenía 1,700 cooperativas con aproximadamente 100,000.00 asociados. En el año 2013 había 4,500 cooperativas con más de 300.000 .00 mil socios $^{19}$.

\section{El rol de las cooperativas en la gestión del medio ambiente}

La protección al medio ambiente ha avanzado notablemente en Nicaragua en los últimos años, percibiéndose mayor conciencia sobre los problemas ambientales, contando con una mejor comprensión de las relaciones directas existentes entre el medio ambiente y desarrollo del país, hecho que se refleja en la ampliación de la agenda ambiental que paulatinamente ha ido permeando hacia los diversos sectores de la actividad económica, social y política. En este sentido, se dispone de una amplia legislación medioambiental estableciéndose derechos y obligaciones para todos, donde los poderes públicos gestionan y supervisan en esta materia. Esto ha llevado a la realización de agendas de trabajo en la aplicación de políticas e instrumentos para la protección ambiental.

No obstante, lo anterior, persisten en Nicaragua grandes problemas de contaminación, destrucción y degradación de los recursos naturales y del medio ambiente, los cuales están asociados a muchos factores, tales como la pobreza la cual incide en los patrones de producción

19 Aburto Cruz, Manuel. 2013. "Nicaragua el país con más cooperativas en Centroamérica», El Nuevo Diario, 5 de febrero, acceso el 13 de diciembre de 2019. https://www. elnuevodiario.com.ni/economia/276568-nicaragua-es-pais-mascooperativas-centroamerica/ 
y consumo dominantes contarios a las normas mínimas de protección ambiental. Por tanto, se requiere de una movilización de recursos materiales y humanos para fortalecer la gestión ambiental y buscar un mejor cumplimiento de la política ambiental, así como crear un mercado que cumpla y se ajuste a estas nuevas políticas.

\subsection{La protección estatal al medio ambiente}

Históricamente, Nicaragua ha estado estrechamente vinculada al aprovechamiento de sus recursos naturales, siendo la base de su economía los bienes provenientes del sector primario (agricultura, ganadería, pesca, explotación forestal y minería). Asimismo, se ha incorporado el sector secundario o industrial (manufacturas y textiles) y el terciario (comercio y turismo).

En materia ambiental existe una profunda contradicción en Nicaragua, dado que este país posee una rica biodiversidad, pero hace un uso insostenible de ella. Desgraciadamente, la pobreza ha marcado (ya fuera por acción, pero especialmente por omisión) las políticas y especialmente las prácticas del manejo de los recursos naturales. El ritmo de consumo de los recursos naturales y la consiguiente contaminación, superan la capacidad de los ecosistemas para recuperarse. Lejos de generar mejores condiciones de vida para la población, se trata de resolver problemas de abastecimiento inmediato, comportamiento éste que agudiza los problemas sustentabilidad a medio y largo plazo. Nicaragua, se ha caracterizado por el uso excesivo de los recursos naturales propiciando la destrucción del medio ambiente, situación que es visible con la contaminación del agua, aire, suelo y el peligro de extinción o la desaparición de especies vegetales y animales, desencadenando otros tipos de problemas como los impactos en la salud o en la migración. El fenómeno del calentamiento global ha tenido una incidencia especialmente negativa ante este panorama tan vulnerable.

Nicaragua se encuentra, por lo tanto, inmersa en un círculo vicioso, en el cual la alternativa más apremiante a la salida de la pobreza tiene consecuencias perjudiciales para el suelo y le medio ambiente, lo que produce agotamiento, erosión del suelo y contaminación generando problemas de salud y modos de vida precarios que se convierten en crónicos.

Las propias políticas públicas del Estado buscan cambios en las formas de producción y consumo de los nicaragüenses, a partir de una definición clara de los problemas actuales producidos por la intervención del hombre y que pasamos a enumerar: 
1. Contaminación del agua por fuentes agrícolas, industriales y domésticas

Nicaragua es un país rico en recursos hídricos. Sin embargo, hay grandes extensiones de tierra áridas o semiáridas, tal como la región de occidente y parte del llamado «corredor seco» ${ }^{20}$. A pesar de los avances, el acceso al agua potable sigue siendo insuficiente, especialmente en las zonas rurales (el $65 \%$ de acceso a agua potable), en casos en que la mejora de los indicadores de salud y nutrición depende directamente de la calidad del agua ${ }^{21}$.

Una de las causas de la contaminación del agua son las cargas orgánicas provenientes de aguas de uso domiciliario que no han sido tratadas. Otras causas de la contaminación hídrica son los residuos industriales como la minería de oro, químicos sintéticos y desechos peligrosos; los basureros y los productos agroquímicos. La contaminación de las aguas propaga enfermedades infecciosas como el cólera, tifoidea y gastroenteritis ${ }^{22}$.

2. La desforestación o tala indiscriminada de árboles

Si bien es cierto que hay prohibición por parte de las autoridades para que no se abuse de la tala de los bosques, no obstante, la capacidad institucional de regulación y control es muy baja, ya que el Ministerio del Ambiente y los Recursos Naturales (MARENA) no dispone de suficientes recursos humanos y financieros. La deforestación se continúa dando fundamentalmente como consecuencia directa del avance de la frontera agrícola para actividades agropecuarias, de la cons-

20 Esta es una extensa área de tierra de 1.600 kilómetros de longitud y de 100 a 400 kilómetros de ancho que inicia en la costa del Pacífico de Chiapas, México, hasta al occidente de Panamá. En Nicaragua el corredor seco comprende en el occidente del país los departamentos de: León y Chinandega; y en la zona norte los departamentos de: Nueva Segovia, Madriz, Estelí y Matagalpa (González Figueroa, Alan. 2012. "Marco estratégico regional para la gestión de riesgos climáticos en el sector agrícola del corredor seco centroamericano». Organización de Naciones Unidas para la Alimentación y la Agricultura. Roma.

21 Servicio Europeo de Acción Exterior. 2014. «Documento de estrategia nacional y programa indicativo plurianual 2014-2020. Nicaragua». Acceso el 4 de enero 2020. https://eeas.europa.eu/sites/eeas/files/20150610_01_es.pdf

22 Lara Benavidez, Rebeca Saray. 2015. «Políticas públicas, sostenibilidad ambiental y desarrollo de Nicaragua». Revista Electrónica de Investigación en Ciencias Económicas de UNAN-Managua, 6: 158-228. Acceso el 7 de diciembre de 2019. https://www. revistasnicaragua.net.ni/index.php/reice/article/view/2011 
trucción de infraestructura y venta de madera y leña para cocinar. Todas estas prácticas inadecuadas constituyen un factor de vulnerabilidad de la cuenca hidrográfica que priva a los suelos de vegetación, dificultando además el desarrollo de las fuentes de energía renovable ${ }^{23}$.

3. Degradación de suelos

La degradación del suelo afecta un porcentaje considerable del área de Nicaragua. Entre las principales causas de la degradación del suelo están la erosión (por deforestación) y la degradación química ${ }^{24}$. Entre los efectos de este problema se encuentran la pérdida de productividad agrícola en algunos territorios de la región, así como su contribución a los procesos de desertificación que degradan la calidad de la tierra y amenazan a regiones áridas, semiáridas y subhúmedas. A su vez, esta degradación reclama un mayor uso de agroquímicos que terminan por inutilizar los suelos.

4. La pérdida de la biodiversidad

La pérdida de la biodiversidad, en buena parte originado por la deforestación y la contaminación de las aguas, es hoy la principal amenaza ambiental en Nicaragua. Entre los mayores problemas se mencionan la fragmentación y destrucción de ecosistemas, el creciente número especies amenazadas y la erosión genética tanto en las zonas naturales como en los agroecosistemas. Aun cuando se han incrementado las áreas protegidas, se continúan enfrentado grandes dificultades con su manejo y muchos ecosistemas del país 25 .

5. El cambio climático

Si bien Nicaragua emite muy bajos índices de contaminación ambiental al planeta, es uno de los más perjudicados en lo que se refiere a la recepción de sus efectos. Su posición geográfica y

23 Aragón, Liliana y Miranda, Miguel. 2013. «Buenas prácticas de mejora ambiental de la gestión institucional». Cooperación Nicaragua-Luxemburgo, 1-69. Acceso el 19 de diciembre de 2019. https://luxdev.lu/files/documents/LuxDev_GUIA_BPA.pdf

24 Alfaro Alemán, Angelica, Sánchez, Mario y Sosa Jirón, Tania. 2018. «Estructura para la defensa del medio ambiente y derechos humanos ante el impacto del extractivo minero en Centroamérica». Alianza Centroamericana frente a la Minería, Centro Humboldt, Managua, 11-126. Acceso el 9 de enero de 2020. http://acafremin.org/images/documentos/Estratgias-para-le-Defensa-delMedioambiente.pdf

25 (Servicio Europeo de Acción Exterior. 2014, 6). 
su vulnerabilidad medioambiental, económica y social son factores que inciden aún más en la vulnerabilidad del país, siendo que el cambio climático incide en Nicaragua de manera especialmente intensa, causando graves daños a la economía nacional de forma recurrente, provocando incluso graves desastres naturales ${ }^{26}$.

La cuestión ambiental está directamente relacionada con las condiciones de desarrollo económico y social del país, con sus seguridades y fortalezas, con sus deficiencias y vulnerabilidades. Es por ello que para su correcta evaluación debemos entrar a evaluar diversas categorías, tales como, el crecimiento poblacional, el ritmo de desarrollo económico, el patrón de distribución del ingreso, los modelos de producción y consumo, el acceso a empleo, acceso a servicios de salud y educación, y otros tantos factores que influyen en las variables ambientales del país, de los que hemos citado, sólo, los más relevantes.

La gestión ambiental en Nicaragua se enmarca dentro un orden normativo e institucional cuyo objetivo ha sido diseñar e implementar planes y programas que vengan a reducir la vulnerabilidad medioambiental. En este sentido, la Constitución nicaragüense (en lo sucesivo $\mathrm{Cn}$ ) en su artículo 60 proclama: "Los nicaragüenses tienen derecho de habitar en un ambiente saludable. Es obligación del Estado la preservación, conservación y rescate del medio ambiente y de los recursos naturales». Y el artículo 102 de la misma norma indica que: «Los recursos naturales son patrimonio nacional. La preservación del ambiente y la conservación, desarrollo y explotación racional de los recursos naturales corresponden al Estado; éste podrá celebrar contratos de explotación racional de estos recursos, cuando el interés nacional lo requiera».

A partir de estos fundamentos constitucionales se ha creado una red institucional de agencias, departamentos o direcciones, entre otras entidades estatales, cuya función unitaria es la aplicación de la normativa nacional y de aquellas disposiciones contenidas en Tratados internacionales a las que se ha adherido Nicaragua.

Entre las normas que rigen el marco jurídico ambiental nicaragüense, se pueden citar, las siguientes: Ley General del Medio Am-

26 Ruiz García, Alfredo y Pelegrín Cruz, Emma. 2017. «Incidencias de la variabilidad y el cambio climático en la opción migratoria de familias habitantes de comunidades de los municipios de El Viejo, La Paz Centro, Ciudad Darío, Managua y Tola». Cuadernos de Investigación n. ${ }^{\circ}$ 31: 39-68. 
biente y los Recursos Naturales27, Ley General de Aguas Nacionales ${ }^{28}$, Ley de Contrataciones Administrativas del Estado ${ }^{29}$, Ley General de Salud $^{30}$, Ley General de Turismo31, Reglamento de Áreas Protegidas 32 , Decreto sobre Sistema de Evaluación Ambiental ${ }^{33}$, Decreto de Política Nacional sobre Gestión Integral de Residuos Sólidos ${ }^{34}$, Decreto que Establece la Política Nacional de Recursos Hídricos ${ }^{35}$, Decreto sobre Creación de Unidades de Gestión Ambienta ${ }^{36}$.

A pesar de los avances legales es necesario precisar algunos aspectos. De manera general, es evidente la existencia de una abundante legislación ambiental, la cual se ha incrementado de forma exponencial en los últimos años. Pero también se hace evidente el bajo cumplimiento de dicha legislación, provocado por los insuficientes mecanismos a su servicio como una falta de concienciación ciudadana.

Lo anterior vuelve a mostrar la ineficacia de una excesiva labor legislativa, cuando no se cuenta con los instrumentos o recursos favorables a su aplicación. Además, muchas veces ello se traduce en una grave dispersión de tales disposiciones, contradicciones o incluso aplicaciones irracionales, deteriorando la credibilidad de los propios funcionarios.

La baja capacidad operativa, técnica, financiera e institucional para aplicar las disposiciones ambientales, para hacer seguimiento a sus obligaciones o para ejercer las funciones de control y vigilancia, así como la falta de una verdadera voluntad política que respalde estas normas, ha dificultado la aplicación efectiva del derecho ambiental. 2014)

27 Ley 217/2014, de 17 de enero (La Gaceta Diario Oficial n. ${ }^{\circ} 20$ de 31 de enero de

28 Ley 620/2007, de 15 de mayo (La Gaceta Diario Oficial n. ${ }^{\circ} 169$ de 4 de septiembre de 2007).

29 Ley 737/2010, de 19 de octubre (La Gaceta Diario Oficial n. ${ }^{\circ} 213$ y 214, de 8 y 9 de noviembre de 2010). 2002).

30 Ley 423/2002, de 14 de marzo (La Gaceta Diario Oficial n. 91 de 17 de mayo de

31 Ley 495/2004, de 2 de julio (La Gaceta Diario Oficial n. ${ }^{\circ} 184$ de 22 de septiembre de 2004).

32 Decreto-ejecutivo 01-2007, de 8 de enero (La Gaceta Diario Oficial n. ${ }^{\circ} 8$ de 11 de enero de 2007).

${ }^{33}$ Decreto 76-2006, de 19 de diciembre (La Gaceta Diario Oficial n. ${ }^{\circ} 248$ de 22 de diciembre de 2002).

34 Decreto-ejecutivo N. ${ }^{\circ}$ 47-2005, aprobado el 21 de julio de 2005, publicado en La Gaceta N. ${ }^{\circ} 163$ de 23 de agosto de 2005.

35 Decreto 107-2001, de 21 de noviembre (La Gaceta Diario Oficial n. ${ }^{\circ} 233$ de 7 de diciembre de 2001).

36 Decreto 68-2001, de 12 de julio (La Gaceta Diario Oficial n. ${ }^{\circ} 144$ de 31 de julio de 2001). 
Los objetivos de las políticas ambientales son: la conservación, distribución, prevención y control de la contaminación del agua; el saneamiento básico de los asentamientos humanos y su hábitat; la regulación ambiental de la industria y de las ciudades; la prevención y control de la contaminación atmosférica; el manejo ambiental de sustancias y residuos peligrosos; la prevención y reducción de riesgos ambientales; el aprovechamiento sustentable de los recursos naturales; la conservación y restauración de suelos; y la protección de especies en peligro de extinción y de la biodiversidad.

El Estado nicaragüense ha puesto a disposición de la ciudadanía una serie de instrumentos económicos como medidas de carácter financiero y fiscal que ayudan a fomentar, motivar o incentivar la conducta de los individuos para reducir la contaminación y degradación de los recursos naturales. Así lo señala el artículo 47 de la Ley General de Medio Ambiente y de los Recursos Naturales (en adelante LGMARN) «El Estado fomentará mediante incentivos fiscales la inversión para el reciclaje de desechos domésticos y comerciales para su industrialización y reutilización, acorde a los procedimientos técnicos y sanitarios que aprueben las autoridades competentes». Y el artículo 48 de la misma Ley dice que "se exonerará de impuestos de importación a los equipos y maquinarias conceptualizados como tecnología limpia en su uso, previa certificación del Ministerio del Ambiente y de los Recursos Naturales».

Como puede verse a estos instrumentos se le asignan dos funciones importantes: la de incentivo para reducir la contaminación y fomentar la investigación, y el desarrollo de tecnologías limpias.

También el Estado otorga estímulos morales para la prevención y cuido del medio ambiente, en este sentido, el artículo 41 de la LGMARN dispone que «el Estado hará reconocimiento moral a las personas naturales o jurídicas y a instituciones que se destaquen en la protección de los recursos naturales y del ambiente».

A pesar del interés del Estado mostrado en el respeto y protección del medio ambiente, este interés se reduce, en la práctica, a la parte legislativa. Los problemas por los que atraviesa el gobierno han obligado a una reducción de recursos para colmar incluso los servicios sociales, con efectos muy negativos en materia medioambiental: educación, salud, agua potable, recursos financieros, asistencia técnica, infraestructuras básicas, etcétera. Ante esta situación, muchos de los esfuerzos en implementar de manera efectiva la normativa aprobada por el Estado en esta materia son inaplicables.

Además de los problemas para monitorear el cumplimiento de las leyes y normas ambientales, está la disyuntiva de aplicar con rigor las san- 
ciones correspondientes (e impactar negativamente en una economía de por sí débil) o dejarlas sin efecto. Finalmente, se optó por una salida que cubre objetivos económicos, políticos y ambientales, pero únicamente de forma voluntaria. Se trataría de auditorías ambientales voluntarias.

\subsection{El cuidado del medio ambiente por las cooperativas}

El artículo 55 de la LGMARN determina que «todas las personas naturales o jurídicas, públicas o privadas, están obligadas a participaren la prevención y solución de los problemas originados por los desastres ambientales». De este modo, las cooperativas quedan obligadas a participar en la prevención de riesgos contra el medio ambiente como parte de sus deberes de gestión organizativa ${ }^{37}$. Estas obligaciones son coherentes y deben verse como parte de los principios que sustentan a las cooperativas, tales como la solidaridad, ayuda mutua, participación e interés de la comunidad. Y es que, en Nicaragua, como en otras latitudes, la idea del cooperativismo está íntimamente relacionada con la justicia social. Así se refleja en el aparatado $V$ de la Exposición de Motivos de la LGC proclama que «es responsabilidad del Estado fomentar la educación cooperativa en todo el sistema educativo nacional sobre la base de los principios e idearios del cooperativismo universal, para contribuir a fortalecer una cultura de paz, justicia, equidad y solidaridad, en función del bien común de los cooperados y de la sociedad nicaragüense en general».

El papel de las cooperativas en su lucha contra la degradación del medio ambiente no responde a un plan general de coordinación nacional que aúne esfuerzos hacia una misma dirección que permita la permeabilidad en beneficios y efectos. Desgraciadamente, la precaria financiación ha limitado enormemente su influencia, generándose una atomización de proyectos, muchas veces procedentes de diversas fuentes, sin coordinación entre sí, y con alcances muy reducidos.

Algunas cooperativas, sobre todo las agrícolas, concentran su acción principalmente en programas y proyectos del campo (en la de-

37 El movimiento cooperativo nicaragüense se ha manifestado ante el problema de sostenibilidad ambiental, a partir del XXX Congreso de Alianza Cooperativa Internacional (ACl) celebrado en Tokio, Japón en 1992 cuya convocatoria se hizo con el propósito de tratar este tema y emitir una declaración sobre Medio Ambiente y Desarrollo (Valladares Castillo, Francisco. 1996. Derecho cooperativo en Nicaragua. León: Universidad Nacional Autónoma de Nicaragua). 
nominada Agenda Verde o Ambiental) que son parte de la agenda de los programas de cooperación internacional y las organizaciones no gubernamentales europeas o norteamericanas que constituyen su principal fuente de financiación. Es un fenómeno que puede ser interpretado como un signo positivo en la defensa del medio ambiente, si bien con los inconvenientes señalados.

La movilización cooperativa en torno a la temática ambiental no puede ser vista únicamente como resultado de la existencia de un mecanismo gubernamental a través del cual puede ser incorporada o consultada. Diversas cooperativas han establecido plataformas propias que desbordan a la política oficial, o se realizan a pesar de ella. Resulta relevante el hecho de que estas han asumido un papel más proactivo y participativo en torno a la protección ambiental. No se está hablando aquí del sector cooperativo como objeto de la regulación ambiental sino como protagonista de acciones que van más allá de lo que la Ley le obliga.

Un ejemplo de lo anterior lo encontramos en Sébaco. El 17 de agosto de 2007 se efectuó en el municipio de Sébaco (Matagalpa) un encuentro nacional del movimiento cooperativo nicaragüense con las altas autoridades del país, donde participaron más de dos mil líderes de cooperativas agrícolas, pecuarias, transporte, pesca, agroindustria, ahorro y crédito, de mujeres, etc ${ }^{38}$. De este encuentro nace la «Agenda de Sébaco» con un Plan Estratégico del Movimiento Cooperativo para los años 2007-2020. Los grupos de trabajo incluyeron en la agenda el papel de las cooperativas en la defensa del medio ambiente.

Esta Agenda ya ha significado un paso esencial en el proceso de incorporación de las cooperativas en la defensa y protección del medio ambiente. Así, por ejemplo, han ajustado mecanismos de control, que obligan a los miembros de las cooperativas a cumplir con las normas ambientales, se ha incrementado la concienciación a favor del uso de plaguicidas y herbicidas orgánicos, utilización de técnicas de producción que reducen el consumo de energía y, siempre que sea posible, el recurso a energías renovables que minimizan las emisiones de gases de efecto invernadero, entre otros objetivos.

No obstante, los evidentes avances, aún se presentan muchos obstáculos, además de los ya descritos en este epígrafe. Al no contar

38 López Zepeda, Leonardo Francisco. «La revolución y el desarrollo histórico del cooperativismo en Nicaragua». Revista Electrónica de Investigación en Ciencias Económicas, Departamento de Economía Agrícola, UNAN-Managua, 7 (2016): 216-228. https://revistacienciaseconomicas.unan.edu.ni/index.php/REICE/article/view/104 
las cooperativas nicaragüenses con fondos propios ni tampoco con subvenciones estatales para estos fines, tienen que recurrir a organismos internacionales para financiación de proyectos de investigación e innovación científica y tecnológica que les impulsen no sólo en la práctica de métodos más amigables con el medio ambiente sino también, y como parte de lo anterior, como un incremento de la competitividad de las cadenas agroalimentarias, cada vez más exigentes con la normativa estatal e internacional en esta materia.

\section{Las cooperativas y la exclusión social}

\subsection{La exclusión social en Nicaragua}

Cuando hablamos de exclusión social lo utilizamos como sinónimo de pobreza. No obstante, como señala Arrieta Idiakez, el concepto de exclusión social es más amplio que el de pobreza, ya que engloba tanto las causas como los efectos de la misma, pues se trata de un fenómeno multidimensional dado que se ve condicionado por distintos factores como el empleo, la protección social, la estructura familiar, la vivienda, la educación o la salud ${ }^{39}$. En otras palabras, la pobreza lleva aparejada una privación material para la satisfacción de las necesidades esenciales del ser humano. En cambio, la exclusión social no se asienta exclusivamente en la falta de recursos económicos sino en la privación de los derechos y libertades básicas de la persona.

La exclusión social como concepto multidimensional tiene, al menos, cuatro características interrelacionadas entre sí:

1) La primera es el hecho de que algunos grupos son excluidos a través de formas no económicas que condicionan el capital humano. Hay grupos que no tienen el mismo acceso a la educación, a la salud u otros servicios que predisponen en condiciones diferentes a su inclusión en la sociedad, incluso en igualdad de condiciones económicas de ingresos.

2) La segunda es el acceso desigual a los mercados laborales. Aun para las personas con similares niveles de capital humano y calificación parece haber un importante elemento de discriminación determinado, por ejemplo, por la localización geográfica.

39 Arrieta Idiakez, Francisco Javier. 2017. «La exclusión social de los jóvenes y las cooperativas», Nueva Revista española del Derecho del trabajo, n. ${ }^{\circ}$ 202: 126. 
3) La tercera se refiere a la exclusión de los mecanismos participativos, mecanismos que por medio de la participación de diversos grupos sociales afectan el diseño, la implementación y la evaluación de programas y proyectos del sector público.

4) Finalmente, la cuarta, y la más general de las características, es la exclusión en el sentido del desigual acceso en la práctica al ejercicio completo y protección de los derechos políticos y las libertades civiles, llegándose incluso a sectores con una total negación de derechos básicos.

La exclusión social se vuelve relevante en el pensamiento sobre el desarrollo en América Latina hacia comienzos de la década de los noventa ${ }^{40}$. En la base de la argumentación regional sobre el tema se encuentra la identificación de mecanismos institucionales que regulan la capacidad de cohesión social de una sociedad y que se empiezan a desarrollar en el marco de los procesos de democratización que tienen lugar en la región desde inicios de dicha década. Nicaragua comparte con los demás países de la región latinoamericana un fenómeno social histórico que se remonta, al menos, desde los tiempos de la colonia, a saber, el problema de la pobreza y desigualdad. Se conservan las peculiaridades propias de los contextos históricos y geográficos de cada país respecto a la reproducción de la pobreza; en consecuencia, el alivio o búsqueda de estrategias para la superación de la desigualdad ha sido una constante en las políticas de Estado ${ }^{41}$. Es evidente que la exclusión social en Nicaragua es un fenómeno estructural que no ha permitido establecer un referente de cohesión social, caracterizándose muchas políticas gubernamentales en el sojuzgamiento de un grupo social contra otro. La exclusión social ha dejado secuelas que encontramos en la sociedad actual, sociedades divididas en dos grandes grupos sociales separados a gran distancia uno del otro.

En Nicaragua, el Estado Social constituye un principio estructural en la configuración del orden constitucional que determina la responsabilidad del Estado en el aseguramiento de la libertad e igual-

40 Márquez, Gustavo. 2009. «¿Los de afuera?». En La lucha contra la exclusión social en América Latina: una mirada desde Europa, 183-184. La Paz: BID/Eurosocial/ Comisión Europea/Plural Editores.

41 Gómez Santibáñez, Guillermo y Romero Molina, José Luis. 2009. «Desigualdad y exclusión social en Centroamérica alternativa de políticas públicas. Caso Nicaragua». En Centro de Estudios Latinoamericanos y Caribeños. 7-8. Managua. Acceso 22 de enero de 2020. http://biblioteca.clacso.edu.ar/Nicaragua/cielac-upoli/20140701114049/ desigualdad_exclusion_social_en_nicaragua.pdf 
dad de los ciudadanos y la obtención de las condiciones adecuadas de la vida social. En este sentido, el artículo 6 de la Constitución nicaragüense impone a los poderes del Estado la obligación de promover las condiciones para que la libertad y la igualdad sean efectivos, facilitando la participación de los ciudadanos en la vida política, económica, social y cultural.

La previsión derivada del señalado precepto tiene carácter genérico que se concreta en otras disposiciones constitucionales en los que se contienen los objetivos más precisos y que se identifican con los llamados «principios rectores» de la política social y económica y que hacen referencia a principios de actuación de los poderes públicos relativos a la cobertura de las necesidades sociales, los instrumentos o vías para la consecución de estos objetivos, alguno de ellos traducido en derechos inviolables de la persona, que exigen, como manifestación básica del Estado Social, una redistribución de recursos económicos a cargo del Estado ha incidido en su configuración doctrinal como "derechos sociales» asumidos históricamente por el Estado para los ciudadanos.

\subsection{La exclusión social en las cooperativas}

En Nicaragua, sin obviar el carácter multidimensional de la exclusión social, su manifestación más acuciante se visualiza especialmente en las desigualdades de acceso al empleo y protección social. No sólo porque la pérdida o precariedad en el empleo y las deficiencias de la protección social impiden que el individuo obtenga los recursos económicos necesarios para afrontar las necesidades básicas, tales como educación, vivienda, etc., sino también porque cuando el individuo padece esas deficiencias está quedando al margen de unos de los derechos propios de un Estado social. En este sentido, señala Sánchez-Urán Azaña que la relación entre ambas (empleo y protección social) es proporcionalmente inversa a mayor empleo a los ciudadanos con el menor riesgo de padecer exclusión social42.

Ahora bien, en una economía de capitalismo dependiente como la nicaragüense, el mercado laboral genera desigualdades entre la población económicamente activa (PEA) por muchos factores, entre los que merecen especial atención:

42 Sánchez-Urán Azaña, Yolanda. 2005. «Excluidos sociales: Empleo y protección social», en Revista del Ministerio de Trabajo y Asuntos Sociales, n. ${ }^{\circ}$ 59: 180-181. 


\section{Exclusión por razones de edad}

En este supuesto no se incluye a los menores de edad ya que por disposición legal no se les permite trabajar ${ }^{43}$ sino de las personas que, por razones de su edad, generalmente mayores de 45 o menores 25 años, se encuentran excluidos del mercado laboral ${ }^{44}$.

2. Exclusión por enfermedad o impedimentos físicos

Bajo este epígrafe encontramos como población especialmente vulnerable a las personas que sufren el Virus de Inmunodeficiencia Humana (VIH). En este sentido, las investigaciones realizadas han demostrado que, a pesar de la prohibición legal de discriminación, los portadores de esta enfermedad

43 El artículo 131 del Código Laboral determina que: «La edad mínima para trabajar mediante remuneración laboral es de 14 años, en consecuencia, se prohibe el trabajo a menores de esa edad. A los adolescentes que trabajan se les reconocerá capacidad jurídica para la celebración de contratos de trabajo a partir de los dieciséis años de edad. Los adolescentes comprendidos entre las edades de 14 a 16 años no cumplidos podrán celebrar contratos de trabajo con el permiso de sus padres o representante legal, bajo la supervisión del Ministerio del Trabajo. Corresponderá a la Inspectoría General del Trabajo, a solicitud de parte o de oficio, conocer y sancionar denuncias sobre la violación a esta disposición». Y el artículo 133 del mismo Código prohíbe el desempeño de los adolescentes en trabajos que por su naturaleza, o por las condiciones en que se realiza dañen su salud física, psíquica, condición moral y espiritual, les impida su educación, unidad familiar y desarrollo integral, tales como: a) Trabajos que se realizan en lugares insalubres, minas, subterráneos y basureros. b) Trabajos que implique manipulación de sustancias psicotrópicas o tóxicas. c) Trabajos en centros nocturnos de diversión y otros que, por su naturaleza, vulneren la dignidad y los derechos humanos o se realicen en jornadas nocturnas en general y horarios prolongados. d) Situaciones en que los y las adolescentes quedan expuestos a abusos físicos, psicológicos o explotación sexual comercial. e) Trabajos que se realizan bajo tierra, bajo agua, en alturas peligrosas o en espacios cerrados, temperaturas muy altas o bajas y niveles de ruidos o vibraciones que lesionen su salud tanto física como psíquica. f) Trabajos que se realizan con maquinaria, equipos y herramientas peligrosas, o que conlleven la manipulación o el transporte manual de cargas pesadas. g) Cualquier otro trabajo que implique condiciones especialmente difíciles, que pongan en riesgo la vida, salud, educación, integridad física o psíquica de los y las adolescentes que trabajan. Correspondiendo al Ministerio de Trabajo, conjuntamente con la Comisión Nacional para la Erradicación Progresiva del Trabajo Infantil y del Adolescente Trabajador, definir, revisar y actualizar anualmente el listado de los trabajos peligrosos en consulta con las organizaciones de empleadores, sindicales y de la sociedad civil.

44 Baltodano, Ovielt y Pacheco, Eduardo. 2014. «El mercado laboral de Nicaragua desde un enfoque de género». Cuadernos de Desarrollo Humano, n. ${ }^{\circ}$ 6: 13-14. http:// www.cosep.org.ni/rokdownloads/main/cosep/mercado_laboralenfoque_genero.pdf 
cuando llegan a conseguir un empleo participan en situación de desventaja laboral ${ }^{45}$.

Así, el Estado nicaragüense aprobó la Ley de Promoción, Protección y Defensa de los Derechos Humanos ante el VIH y SIDA para su Prevención y Atención ${ }^{46}$ que en su artículo 13 determina que son derechos de las personas con esta enfermedad: «d) Al trabajo. Las personas con VIH o en condición Sida, tienen igual derecho al trabajo, salario digno y a todas las prestaciones de ley, pudiendo desempeñar labores de acuerdo a sus capacidades físicas y competencia profesional. No podrá considerarse su condición de salud como impedimento para su contratación y estabilidad laboral. Ninguna institución, empresa privada o pública puede obligar a la realización de la prueba de VIH antes y durante la contratación. El estado serológico real o supuesto, no es un motivo para terminar una relación de trabajo para ningún tipo de ocupación en el sector público o privado. A las personas con enfermedades relacionadas con el VIH y que se encuentren aptas según criterio médico-epidemiológico, no se les deberá negar la posibilidad de continuar realizando su trabajo y de ser necesario se harán ajustes razonables a su condición de salud para su desempeño. En el caso de las fuerzas armadas y policiales no podrán ser dados de baja del servicio activo, si se encuentran aptas según criterio médico-epidemiológico, ni será causal para la terminación de la relación laboral y no pago de sus prestaciones de ley».

En cuanto a los impedimentos físicos suponen otra imposibilidad para acceder al empleo por la existencia de múltiples barreras arquitectónicas. En Nicaragua, su historia reciente ha producido una importante tasa de personas con capacidades físicas reducidas y permanentes. Esta realidad que se manifestó de manera generalizada en todo el país llevó a la aprobación de leyes de reinserción de estas personas al mercado laboral, que han tenido bastante éxito tanto en el sector público como privado. En este sentido, se promulgó la Ley de Prevención, Reha-

45 Según la Organización Panamericana de la Salud, en Nicaragua desde 1987 a 2017 se han detectado 12,157 casos de $\mathrm{VIH}$, de los cuales han fallecido 2,429 personas. En la actualidad conviven 9,728 personas con el VIH de una población total de casi 7 millones de habitantes. https://www.elnuevodiario.com.ni/nacionales/430802principales-portadores-vih-nicaragua-hombres-20-39/

${ }_{46}$ Ley 820/2012, de 27 de noviembre (La Gaceta Diario Oficial n. ${ }^{\circ} 242$ de 18 de diciembre de 2012). 
bilitación y Equiparación de Oportunidades para las Personas con Discapacidad ${ }^{47}$.

3. Exclusión por razones políticas e ideológicas

Si bien en Nicaragua existe una genérica prohibición constitucional de discriminación por razones políticas e ideológicas de conformidad con el artículo 27 constitucional, en la práctica es papel mojado, ya que si no se tiene una carta-aval político en muchas empresas públicas o privadas no se le da empleo al solicitante. ${ }^{48}$ Esta situación muy presente en el sector público o privado prácticamente es inexistente en el ámbito de las cooperativas. Ello tiene su sentido en un país donde no reciben subvenciones estatales y que, por tanto, se privilegia el mérito y el trabajo.

4. Exclusión por razones de género

Hasta el año 2007, las empresas podían someter a las mujeres que solicitaban empleo a una prueba de embarazo, de cuyo resultado se hacía depender su contratación. Con el objeto de eliminar esta forma de discriminación social, a través del Ministerio del Trabajo se aprobó el Acuerdo Ministerial «Relativo a los Exámenes Médicos en los Lugares de Trabajo ${ }^{49}$ que en su artículo 1 prescribe: «La presente normativa tiene como objeto garantizar el cumplimiento al principio de no discriminación en el acceso al trabajo, de la mujer embarazada, así como complementar lo relativo a los exámenes médicos preempleo. Los Inspectores del Trabajo estarán a cargo de la aplicación de esta normativa e implementarán un sistema de inspección para garantizar la igualdad de condiciones y oportunidades de empleo de la mujer embarazada».

5. Exclusión por razones étnicas

Si bien es cierto que las personas y pueblos indígenas son vulnerables a la exclusión social en casi la mayoría de los países

47 Ley 202/ 1995, de 23 de agosto (La Gaceta Diario Oficial n. ${ }^{\circ} 180$ de 27 de septiembre de 1995).

48 Contreras, Félix. 2011. Déficits de Institucionalidad democrática en Nicaragua y su impacto en el Desarrollo económico, político y social. Managua: Fundación Friedrich Ebert. En el mismo sentido, Otero, Cirilo Antonio. 2017. «La exclusión social en Nicaragua». Opinión en el Diario La Prensa. Acceso el 2 de febrero. https://www. laprensa.com.ni/2017/05/23/opinion/2233769-exclusion-social-en-nicaragua

49 Acuerdo N. $^{\circ}$ JCHG-005-05-07 de 15 de mayo de 2007 (La Gaceta N. ${ }^{\circ} 123$ de 29 de junio de 2007). 
de América Latina, producto de las injusticas sufridas como resultado, especialmente, de los procesos de independencia que conllevaron la enajenación de sus tierras y recursos, podemos decir que en Nicaragua ese fenómeno es prácticamente inexistente. No obstante, la Constitución ${ }^{50}$ y las leyes reconocen la identidad de las personas indígenas y afrodescendientes y las de sus pueblos, con sus derechos y tradiciones. Encontramos en Nicaragua cooperativas exclusivamente de indígenas y también mixtas.

6. Exclusión social por orientación sexual

Bajo este rubro, tampoco encontramos evidentes causas para la exclusión social en el ámbito laboral. En este sentido, hay un marco jurídico de medidas integrales que sirven de base para el equilibrio del colectivo LGTBI ${ }^{51}$. No obstante, el matrimonio entre personas del mismo sexo no está amparado por la Ley, manteniéndose en la actualidad una lucha para el reconocimiento de este y otros derechos derivados. Tampoco, existe una Ley de Identidad de Género, ni ningún mecanismo legal para que las personas que pertenecen a este colectivo puedan realizar cambio de género y de nombre ${ }^{52}$.

50 El artículo 5 párrafo sexto de la Cn expresa: «El Estado reconoce la existencia de los pueblos originarios y afrodescendientes, que gozan de los derechos, deberes y garantías consignados en la Constitución y en especial, los de mantener y desarrollar su identidad y cultura, tener sus propias formas de organización social y administrar sus asuntos locales; así como mantener las formas comunales de propiedad de sus tierras y el goce, uso y disfrute, todo de conformidad con la Ley. Para las comunidades de la Costa Caribe se establece el régimen de autonomía en la presente Constitución».

51 La Cn en su artículo 46 reconoce los derechos fundamentales inherentes a las personas, haciendo referencias a diferentes Tratados internacionales suscritos por Nicaragua: «En el territorio nacional toda persona goza de la protección estatal y del reconocimiento de los derechos inherentes a la persona humana, del irrestricto respeto, promoción y protección de los derechos humanos y de la plena vigencia de los derechos consignados en la Declaración Universal de los Derechos Humanos; en la Declaración Americana de Derechos y Deberes del Hombre; en el Pacto Internacional de Derechos Económicos, Sociales y Culturales; en el Pacto Internacional de Derechos Civiles y Políticos de la Organización de las Naciones Unidas; y en la Convención Americana de Derechos Humanos de la organización de Estados Americanos». Asimismo, en su artículo 27 de la misma Constitución recoge el principio de igualdad ante la Ley, sin embargo, no menciona expresamente motivos de orientación sexual, ni identidad de género.

52 Moreno Areso, Leyre. 2018. «Nicaragua: Situación del colectivo LGTBI». Comisión Española de Ayuda al Refugiado. https://boletinderechoshumanos.files. wordpress.com/2019/01/lgtb-nicaragua-2018.pdf 
Ante esta caracterización de las exclusiones más relevantes en las sociedades actuales de nuestro entorno, pretendemos plantear el papel de las cooperativas como modelos de inclusión social, las cuales ya han demostrado su valor, especialmente en relación a las desigualdades económicas, para ir extendiendo su conceptualización a otras áreas de exclusión social.

La existencia de las cooperativas como figura asociativa con características propias encuentra su fundamento e importancia en los factores económicos y sociales. Como se puso de relieve en el primer epígrafe, la historia de esta institución viene determinada por los factores que impulsaron su origen como instrumento jurídico que respondía a una realidad económica.

La incapacidad del mercado y del sector público para satisfacer convenientemente determinadas necesidades colectivas ha propiciado la aparición de nuevas formas de organización que se agruparon bajo el término de economía social, donde las sociedades cooperativas son la entidad de mayor significación histórica y económica que la integra. Las cooperativas son agentes de desarrollo económico y social presentes en todos los sectores. Téngase en cuenta que las cooperativas son una organización de carácter empresarial que postula una serie de principios y valores que informan su naturaleza peculiar.

En este sentido, el artículo 8 la LGC de Nicaragua expresa que: "Las cooperativas se rigen por los siguientes principios: a) Libre ingreso y retiro voluntario de los asociados. b) Voluntariedad solidaria, que implica compromiso recíproco y su cumplimiento y prácticas leales. c) Control democrático: Un asociado, un voto. d) Limitación de interés a las aportaciones de los asociados, si se reconociera alguno. e) Equidad, que implica la distribución de excedentes en proporción directa con la participación en las operaciones. f) Respeto y defensa de su autonomía e independencia. g) Educación cooperativa. h) Fomento de la cooperación entre cooperativas. i) Solidaridad entre los asociados. j) Igualdad en derecho y oportunidades para asociados de ambos sexos».

Estos principios cooperativos se presentan como la base para cualquier desarrollo sostenible y, por ello, deben regir la actuación en este tipo de sociedades empresariales. Además, se caracterizan por un espíritu comunitario, el cual sienta también las bases del desarrollo al promover valores como la solidaridad, cooperación, equidad, educación, igualdad, la autogestión y la participación de los individuos en un determinado proyecto.

Si bien las cooperativas surgieron en un momento determinado respondiendo a demandas y necesidades concretas y a contextos culturales igualmente específicos, los principios y valores que las origina- 
ron no son ni mucho menos obsoletos, sino que se mantienen vigentes y cobran un sentido especial a la luz de los nuevos contextos socioculturales. De ahí la necesidad de recuperar esta figura y retomarla desde toda su extensión, convirtiéndola en herramienta al rescate de sectores definidos hoy como «vulnerables», es decir, excluidos socialmente.

La cooperativa se erige de por sí en un instrumento importante de reforma social en las relaciones capital-trabajo, que se traduce en la autogestión de la empresa por parte de los trabajadores, tales como la participación en la gestión, en los beneficios o en la propiedad del medio productivo. De conformidad con lo anterior, las cooperativas como empresas participativas desempeñan un importante papel para el desarrollo de grupos interesados en encontrar un espacio de reivindicación dentro de la sociedad, asumiendo un papel activo y generativo de empoderamiento personal y colectivo.

De ahí la razón de su éxito en todo tipo de sociedades, especialmente donde las desigualdades son más acuciantes. Esto se refleja en el incremento de cooperativas en los últimos años en Nicaragua ${ }^{53}$. Hay que señalar que los nombres de las cooperativas no responden, generalmente, a la recuperación social de un sector social concreto, sino que los individuos excluidos socialmente se integran sin barreras en estas organizaciones. Excepciones muy escasas encontramos únicamente en relación a cooperativas fundadas sobre criterios de género o edad, en cuyos casos sus nombres delatan su objetivo concreto, como, por ejemplo, "cooperativa de mujeres productoras de Yalagüina»o "cooperativa de indígenas de Sutiaba».

Y es que el rol del individuo dentro de la cooperativa se adecúa a las propias posibilidades y habilidades concretas que, al ponerlas en común, se multiplica el fruto bajo parámetros de solidaridad y cooperación mutua. Las empresas cooperativas hacen una labor social que abarca a la persona en todos sus aspectos y le da posibilidades para poder crecer, formarse y participar en la sociedad beneficiándolas a ellas personalmente, ya que guía a la persona a pesar de las dificultades que supone todo el proceso; y a la sociedad en general porque reduce la tasa de empleo y aumenta la igualdad de oportunidades.

En consecuencia, partiendo de la premisa de que no existe un único modelo de desarrollo, las cooperativas son un motor de desarrollo local sostenible fundamentado en la utilización de recursos endógenos o propios, en perseguir objetivos tanto económicos como sociales para sus grupos de interés y en desarrollar su actividad de forma

53 Véase nota al pie 18. 
responsable, colaborando así en la construcción de un modelo de desarrollo fundamentado sobre la autoayuda, la movilización de las fuerzas locales y la promoción del potencial endógeno de crecimiento.

Con todo ello, las cooperativas sirven a la comunidad, promoviendo un sentido de responsabilidad social, y tratando de paliar el conjunto de problemas que dificultan la capacidad de adaptación laboral de determinados sectores de población. Así lo ha señalado el párrafo IV de la Exposición de Motivos de la LGC al decir que «Corresponde al gobierno de la República, junto con el movimiento cooperativo, promover la incorporación voluntaria de los nicaragüenses de los diferentes sectores económicos de la nación a organizarse en cooperativas para impulsar las actividades productivas del sector». Y el artículo 2 de la señalada Ley determina que esta norma es «de interés económico y social de la nación, la promoción, fomento y protección del movimiento cooperativo como instrumento eficaz para el desarrollo del sector cooperativo, construyendo así al desarrollo de la democracia participativa y la justicia social».

Por su parte, el sector público ha valorado históricamente el desarrollo cooperativo, en particular en aquellas regiones geográficas y aquellos rubros donde la acción del Estado y de la iniciativa privada clásica es débil o inexistente.

\section{Las cooperativas y la protección social de sus socios}

\subsection{Nociones generales de la Seguridad Social en Nicaragua}

Desde los años sesenta del siglo pasado, Latinoamérica impulsó reformas sociales que vinieron a beneficiar a capas sociales hasta entonces desprotegidas en ámbitos tan cruciales como la salud o la educación, entre otras ${ }^{54}$. No obstante, estos avances no llegaron a toda

54 La evolución histórica de la prevención social en Nicaragua ha sido paulatina se inició con el Decreto sobre Jubilación a los Maestros de Enseñanza Primaria, aprobado el 11 de enero de 1926, publicado en La Gaceta Diario Oficial n. ${ }^{\circ} 243$ de 27 de octubre de 1926. Posteriormente se aprueba el 15 de julio de 1930 y se publica en La Gaceta Diario Oficial n. 153 de 16 de julio de 1930, la Ley de Jubilación del Magisterio Mayores de Sesenta Años de Edad, con un Período Mínimo de Veinte Años de Servicio Docente. El 23 de marzo de 1939 se promulga la Constitución política que proclamó por primera vez que: «El Estado procurará la creación de un Instituto Nacional de Seguros Sociales» (art. 104 Cn) y el art. 105 de la misma Constitución decía «la ley regulará la forma de establecer el fondo de seguros a favor de los asalariados, mediante racional concurrencia del beneficiario y del patrón, para cubrir los riesgos de 
la población y ello por diferentes factores. El mercado informal laboral${ }^{55}$ cubre extensos segmentos de la población, reduciendo la capacidad adquisitiva del Estado que la obliga a limitar los recursos a grupos muy reducidos de la sociedad. Si bien este constituye el factor principal, otras razones culturales e idiosincráticas vienen a obstaculizar este logro: corrupción, deficiencias burocráticas, ausencia de infraestructuras, etc. Avendaño Castellón hace hincapié en otro factor igualmente relevante. Así, para este autor una de las principales causas de la deficiencia en la cobertura de los servicios sociales es el aumento de la esperanza de vida de los habitantes, que determina una proporción cada vez menor de contribuyentes activos en relación a los pensionados ${ }^{56}$. Sobre este aspecto, la Dirección General de Cooperación Internacional y Desarrollo de la Unión Europea señala que Nicaragua está sufriendo en la actualidad una transición demográfica, con el descenso de las tasas de fertilidad y una creciente población joven (el $55 \%$ de la población tiene menos de 25 años) ${ }^{57}$. No obstante, esta misma institución

enfermedad, invalidez, ancianidad y desocupación». Posteriormente se dictó en 1940 el Reglamento de Jubilación, Pensiones y Subsidios de Obreros y Empleados Ferroviarios. El 23 de noviembre de 1944 se aprobó el primer Código del Trabajo, que fue publicado en La Gaceta Diario Oficial n. ${ }^{\circ} 23$ de 1 de febrero de 1945. El 2 de julio de 1952 aprobó mediante Decreto n. 41 la creación del Ministerio del Trabajo como Secretaría del Estado, responsable de la aplicación del Código del Trabajo y del Seguro Social, publicado en La Gaceta Diario Oficial n. ${ }^{\circ} 153$ de 8 de julio de 1952. Luego el 17 de febrero de 1953, se aprobó mediante Decreto Ejecutivo n. ${ }^{\circ}$ 7, publicado en La Gaceta Diario Oficial n. ${ }^{\circ} 45$ de 24 de febrero de 1953 el Reglamento de Fondo de Pensiones y Ahorro para Empleados de la Banca Nacional que se había aprobado mediante Ley el 26 de octubre de 1940. El 9 de mayo de 1955 se aprobó el Decreto n. ${ }^{\circ}$ 1, publicado en La Gaceta Diario Oficial n. ${ }^{\circ} 109$ de 18 de mayo de 1955 que crea la Comisión Planificadora del Instituto Nacional de Seguridad Social. El 11 de noviembre de 1955, se aprueba la Ley Orgánica de Seguridad Social, publicada en La Gaceta Diario Oficial n. ${ }^{\circ} 1$ de 2 de enero de 1956, donde se establece el seguro social obligatorio como parte del sistema de seguridad social con un carácter de servicio público, creándose el Instituto Nicaragüense de Seguridad Social como ente autónomo para que atienda de forma exclusiva a los trabajadores asalariados frente a las siguientes contingencias: enfermedad, maternidad, invalidez, vejez, muerte y sobrevivientes y riesgos laboral (Martínez Rivera, Eddy. 2010. Derecho de la seguridad social. Managua: Universidad Centroamericana. En el mismo sentido, Navarro Medal, Karlos. 2003. La Seguridad Social en Nicaragua: Antecedentes histórico-jurídicos. Managua: Bitecsa).

55 La CEPAL a este sector informal de la economía le denomina también «sectores de baja productividad» que se caracteriza por la falta de relaciones laborales registrada bajo contrato laboral y que presenta porcentajes de cotización al sistema de pensiones extremadamente bajos y sustancialmente menores que los registrados en el sector formal de la economía.

56 Avendaño Castellón, Néstor. 2001. El sistema de salud en Nicaragua. Managua: Publicaciones Friedrich Ebert Foundation.

57 (Servicio Europeo de Acción Exterior. 2014). 
reconoce en este contexto existe una oportunidad única para cambiar la estructura del mercado de trabajo e impulsar el desarrollo económico y social del país, pero siempre y cuando la economía productiva ofrezca más oportunidades a los jóvenes y la educación pueda salvar la brecha entre la oferta y la demanda en el mercado de trabajo ${ }^{58}$.

La Constitución nicaragüense en su artículo 61 proclama que: «El Estado garantiza a los nicaragüenses el derecho a la Seguridad Social para su protección integral frente a las contingencias sociales de la vida y el trabajo, en la forma y condiciones que determine la ley»; y en su artículo 82 de la misma Constitución dice que «los trabajadores tienen derecho a condiciones de trabajo que les aseguren en especial: (...) 7. Seguridad Social para protección integral y medios de subsistencia en casos de invalidez, vejez, riesgos profesionales, enfermedad y maternidad; y a sus familiares en casos de muerte, en la forma y condiciones que determine la ley».

La brecha entre la proclamación constitucional y la realidad sigue siendo grave, no es uniforme y enfrenta muchísimos desafíos. Sólo una cuarta parte de la población está cubierta por el sistema que corresponde básicamente a su sector formal, el cual se concentra en la capital y las principales ciudades del país (León, Chinandega o Matagalpa). Nicaragua se encuentra en los cinco países de Latinoamérica con cobertura poblacional más baja en Seguridad Social (Guatemala, Honduras, República Dominicana y Haití). ${ }^{59}$ El grado de informalidad de la fuerza de trabajo es de más del $60 \%$, lo que dificulta la extensión de la cobertura. Casi la mitad de la población radica en la zona rural y en otros departamentos semirurales ${ }^{60}$.

Con el objeto de paliar estas deficiencias, en el año 2005 se aprueba Ley de Reforma a la Seguridad Social61 (en adelante LSS), cuyo artículo 6 recoge un sistema que busca ampliar la cobertura a otros sectores sociales no incluidos en el sistema formal. El método de inclusión es la cotización voluntaria al sistema.

58 (Servicio Europeo de Acción Exterior. 2014).

59 Organización Internacional del Trabajo. 2018. «Presente y futuro de la protección social en América Latina y el Caribe». Panorama Temático Laboral. Publicaciones: Oficina Regional para América Latina y el Caribe. Acceso el 14 de diciembre de 2019. https://www.ilo.org/americas/publicaciones/WCMS_633654/lang--es/index.htm

60 Navarro Medal, Karlos. 2018. «Repeal of the privatization of the pension system in Nicaragua, extension of social security», Reversing Pension Privatizations: Rebuilding public pension systems in Eastern Europe and Latin America, ILO, paper n. ${ }^{\circ} 70:$ 284-285.

61 Ley 539/2005, de 12 de mayo (La Gaceta Diario Oficial n. 225 de 20 de noviembre de 2006). Esta Ley, derogo el Decreto-Legislativo 974/1982, de 11 de febrero (La Gaceta Diario Oficial n. ${ }^{\circ} 42$ de 1 de marzo de 1982). 
Dicho artículo 8 señala expresamente que «sobre la base del Principio de Universalidad y Solidaridad, podrán inscribirse en el Régimen Facultativo: (...) 5. Los trabajadores por cuenta propia». De este modo, se pueden afiliar al Seguro Social las personas físicas que no están sujetas al seguro obligatorio, al que hace referencia el art. 5 de dicha Ley ${ }^{62}$. El régimen facultativo tiene dos modalidades: 1) facultativo integral que comprende enfermedad, maternidad, invalidez, vejez y muerte; y 2) facultativo por invalidez, vejez y muerte.

En la práctica, es un sistema que queda igualmente fuera del alcance de muchos autónomos y es que la contribución que deben pagar es muy elevada y corresponde a más de tres veces la del trabajador asalariado en el régimen integral, debido a la falta de empleador que es el que aporta el grueso de la cotización cuando existe una relación de dependencia. La crisis económica en Nicaragua forzó al gobierno a elevar todavía más la tasa de cotización en la última reforma al Reglamento de la Ley de Seguridad Social de 201963, pasando de $18.25 \%$ del salario al $22.25 \%$ y en la del facultativo de invalidez maternidad y muerte subiendo del $10 \%$ al $14 \%$. Este hecho movilizó a la población que salió a las calles de forma masiva y apoyadas por el empresa-

62 De acuerdo con este precepto están «sujetos de aseguramiento obligatorio las personas que se encuentren comprendidas dentro de las siguientes normas: a) Las personas nacionales y extranjeros residentes que mediante una relación laboral verbal o escrita, o por cualquier tipo de contratación en calidad de dependiente o independiente por la realización de obras o servicios, sea en forma temporal o permanente con vinculo a un empleador sea este persona natural o jurídica, entidad privada, estatal, mixta, o institución u organismo extranjero residente o no en el país e incluyendo a los organismos e instituciones de Integración Centroamericana. Independientemente de la cantidad de trabajadores, el empleador está sujeto al aseguramiento obligatorio. De igual manera son sujetos de aseguramiento obligatorios las personas que se desempeñen en el ejercicio de la función pública sean electos o nombrados en las instituciones y Poderes del Estado; b) Los trabajadores agrícolas, domésticos y del transporte de acuerdo a las condiciones y peculiaridades de sus trabajos; c) Los nicaragüenses y extranjeros residentes que prestan sus servicios en misiones diplomáticas y organismos internacionales acreditados en el país, de conformidad con los convenios internacionales ratificados por Nicaragua; d) Todos los integrantes o beneficiarios de los programas de Reforma Agraria, ya sea bajo la forma cooperativa, colectiva, parcelamiento o cualquier sistema que adopte el ministerio respectivo; e) Los miembros de asociaciones gremiales de profesionales y demás trabajadores independientes que se encuentren debidamente organizados; f) Los miembros de cooperativas debidamente reconocidas».

63 Decreto 06/2019, de 28 de enero, por el que se reforma el Reglamento de la Ley de Seguridad Social (La Gaceta Diario Oficial n. ${ }^{\circ} 21$ de 1 de febrero de 2019).

${ }_{64}$ El aporte del Estado para el seguro facultativo es del $0.25 \%$ para el régimen de invalidez, vejez y muerte y del 0.50 para el régimen que comprende el aporte solidario para el Sistema Nacional Único de Salud (art. 29 LSS). 
riado. Definitivamente, el alza de las cotizaciones a la Seguridad Social se convirtió en el símbolo de la ruptura definitiva de un pueblo con un sistema que hasta entonces había sobrevivido gracias a un modelo corporativista. Esta brecha se mantiene hasta el día de hoy.

\subsection{El régimen de Seguridad Social de las cooperativas}

Como ya señalábamos anteriormente, la tipología de las cooperativas en Nicaragua responde a un modelo de listas abiertas, siendo que el artículo 14 de la LGC únicamente menciona alguna de ellas, sin contemplar todas las posibles. Así, y en atención a esta norma, en Nicaragua existen cooperativas de consumo, de ahorro y crédito, de vivienda, de producción, etc.

Ahora bien, el artículo 5 de la LSS indica una peculiaridad muy interesante con respecto a la temática que nos ocupa en este epígrafe. Dicha disposición reza así: "Sobre la base de los principios de Universalidad, Integralidad e Igualdad son sujetos de aseguramiento obligatorio las personas que se encuentren comprendidas dentro de las siguientes normas: (...) f) Los miembros de cooperativas de producción debidamente reconocidas» (la negrita es nuestra).

Puede observarse, por tanto, que el único tipo de cooperativas a las que la ley somete a un régimen de suscripción obligatoria es la cooperativa de producción y de trabajo. Las cooperativas de producción son aquellas que tienen por objeto proporcionar trabajo a sus socios, mediante su esfuerzo personal y directo ${ }^{65}$. Este tipo de cooperativas siempre habrá de contar con un mínimo de socios, los cuales han de ser todos trabajadores de la misma (art. 19 LGC). Por su parte, la cooperativa de producción puede contratar a su vez trabajadores asalariados que no sean socios de ella. En estos casos, la cooperativa queda obligada al pago de la cotización por parte del trabajador. Ambos sujetos se circunscriben al sistema general de la Seguridad Social.

En realidad, la contribución de las cooperativas de producción a la Seguridad Social es, proporcionalmente, muy bajo. Sería interesante ahondar sobre la realidad empírica que ponga en correspondencia la existencia de cooperativas debidamente reconocidas y su reflejo en la tesorería. Téngase en cuenta que Nicaragua es uno de

65 Gadea, Enrique, Sacristán, Fernando y Vargas Vasserot Carlos. 2009. Régimen jurídico de la sociedad cooperativa del siglo XXI. Realidad actual y propuesta de reforma. Madrid: Dykinson. 
los países de America Latina donde el modelo de la cooperativa es más fuerte.

Por su parte, es de señalar que ni la LGC ni su Reglamento, en ninguno de sus preceptos hace referencia a la Seguridad Social.

\section{Conclusiones}

Nicaragua al igual que los demás países de Latinoamérica nos presenta una historia económica caracterizada por la persistente existencia de pequeños grupúsculos de poder económico cerrados e impermeables, accesibles únicamente a la alta burguesía. Esta situación excluía a las grandes masas de población de cualquier intervención en el mercado que no fuera a través de su mano de obra, la gran mayoría de las veces en calidad de servidumbre.

El cooperativismo emerge como una figura novedosa, de liberación y de refugio para un importante sector de la sociedad que en relación directa con una actividad económica de producción puede convertirse en propietario y participar del destino, uso y gestión de su trabajo y, por supuesto, de sus beneficios.

A partir de este escenario, las conclusiones más importantes que hemos deducido del presente estudio del cooperativismo en Nicaragua son las siguientes:

1. El cooperativismo en Nicaragua tiene una larga trayectoria histórica que, si bien ha repuntado en ciertos momentos de manera más sobresaliente que en otros, puede afirmarse que es una constante en la realidad económica del país, siendo Nicaragua en la actualidad el país centroamericano con el mayor número de cooperativas. Ello convierte a la cooperativa en merecedora de un lugar privilegiado dentro de la agenda política y económica del país.

2. Las cooperativas en Nicaragua van actuando lentamente en el tejido social y cultural del país en todos sus órdenes. Si, por un lado, se deja atrás la visión única de la cooperativa como elemento de integración del excluido, ofreciéndose, así como elemento democrático integrador, por otro lado, se funge como canalizador de reivindicación política, como respuesta unitaria ante posibles injusticias desde el poder público.

3. El efecto del cooperativismo en la protección del medio ambiente es leve por cuanto una infraestructura adecuada requiere de capacitación, inversión y seguimiento técnico, lo cual 
ha sido si no deficiente, insuficiente. En este sentido, la capacidad de influencia depende en gran medida de la voluntad y disponibilidad de los órganos estatales. No obstante, encontramos alguna cooperativa enfocada al cumplimiento de esta responsabilidad apoyada, en todo caso, en fondos de cooperación extranjera.

4. En cuanto a la exclusión social, la cooperativa se mantiene como elemento integrador de valor indiscutible. A lo largo de los años se han venido incorporando al mercado nuevas cooperativas aglomerando a una proporción cada vez mayor del país, creando empleo y fuentes de ingreso a muchas familias nicaragüenses.

5. A pesar de la importante incidencia de la cooperativa en el país como fuente de empleo y recursos, sus efectos en la protección efectiva de sus miembros en relación la Seguridad Social es escasa. Por un lado, su limitación obligatoria a las cooperativas de producción en las que el socio es trabajador deja fuera al resto de tipologías; por otro lado, en el ámbito de la producción, aún nos encontramos con un importante sector de pequeño propietario no cooperativista.

6. Por último, al margen de los importantes avances señalados, el desarrollo del cooperativismo adolece de deficiencias que no le han permitido convertirse en un generador de mayor poder económico de estos grupos a pesar de su gran potencial: falta de capacitación técnica, recursos para la inversión o mejoramiento de infraestructuras. Si ponemos el acento en deficiencias de origen interno, nos encontramos con actitudes conformistas, visiones cortoplacistas y un cierto temor al riesgo, muchas veces justificado por gobiernos inestables.

\section{Bibliografía}

ABURTO CRUZ, Manuel. 2013. "Nicaragua el país con más cooperativas en Centroamérica», El Nuevo Diario, 5 de febrero, acceso el 13 de diciembre de 2019. https://www.elnuevodiario.com.ni/economia/276568-nicaraguaes-pais-mas-cooperativas-centroamerica/

ALEMÁN, Estela, et al. 1992. Revolución, ajuste económico y el cooperativismo agrario en Nicaragua 1979-1991. Managua: Universidad Nacional Autónoma de Nicaragua.

ALFARO ALEMÁN, Angelica, SÁNCHEZ, Mario y SOSA JIRÓN, Tania. 2018. «Estructura para la defensa del medio ambiente y derechos humanos ante 
el impacto del extractivo minero en Centroamérica». Alianza Centroamericana frente a la Minería, Centro Humboldt, Managua, 11-126. Acceso el 9 de enero de 2020. http://acafremin.org/images/documentos/Estratgiaspara-le-Defensa-del-Medioambiente.pdf

ARAGÓN, Liliana y MIRANDA, Miguel. 2013. «Buenas prácticas de mejora ambiental de la gestión institucional». Cooperación Nicaragua-Luxemburgo, 1-69. Acceso el 19 de diciembre de 2019. https://luxdev.lu/files/documents/LuxDev_GUIA_BPA.pdf

ARNÁEZ ARCE, Vega María. 2018. "La alternativa cooperativa en la prestación de servicios públicos sostenibles», Boletín de la Asociación Internacional de Derecho Cooperativo, n. ${ }^{\circ}$ 52: 123-135. DOI: http://dx.doi.org/10.18543/ baidc-52-2018pp123-135.

ARRIETA IDIAKEZ, Francisco Javier. 2017. «La exclusión social de los jóvenes y las cooperativas», Nueva Revista española del Derecho del trabajo, n. ${ }^{\circ}$ 202: 123-154.

AVENDAÑO CASTELLÓN, Néstor. 2001. El sistema de salud en Nicaragua. Managua: Publicaciones Friedrich Ebert Foundation.

BALTODANO, Ovielt y Pacheco, Eduardo. 2014. «El mercado laboral de Nicaragua desde un enfoque de género». Cuadernos de Desarrollo Humano, n. ${ }^{\circ}$ 6: 8-51. http://www.cosep.org.ni/rokdownloads/main/cosep/mercado_ laboralenfoque_genero.pdf

CARRIÓN CRUZ, Luis. 1988. "Nicaragua pasa hambre» El País, 13 de noviembre. Acceso el 24 de nombre de 2019. https://elpais.com/diario/1988/11/01/internacional/594342012_850215.html

CONTRERAS, Félix. 2011. Déficits de Institucionalidad democrática en Nicaragua y su impacto en el Desarrollo económico, político y social. Managua: Fundación Friedrich Ebert.

FITZGERALD, Valpy y CHAMORRO, Amalia. 1987. "Las cooperativas en el proyecto de transición en Nicaragua», Encuentro, n. ${ }^{\circ}$ 30: 21-45.

FLORES RIVAS, María HAYDE. 1988. La reforma agraria. León: Universitaria.

GADEA, Enrique, SACRISTÁN, Fernando y VARGAS VASSEROT, Carlos. 2009. Régimen jurídico de la sociedad cooperativa del siglo XXI. Realidad actual y propuesta de reforma. Madrid: Dykinson.

GÓMEZ IZABA, Erwin. 1979. "Apuntes sobre la historia del movimiento cooperativo en Nicaragua». Cooperativas en Centroamérica, Historia y Marco Jurídico, s/n: 213-223.

GÓMEZ SANTIBÁÑEZ, Guillermo y ROMERO MOLINA, José Luis. 2009. «Desigualdad y exclusión social en centroamérica alternativa de políticas públicas. Caso Nicaragua». En Centro de Estudios Latinoamericanos y Caribeños. 3-28. Managua. Acceso 22 de enero de 2020. http://biblioteca. clacso.edu.ar/Nicaragua/cielacupoli/20140701114049/desigualdad_exclusion_social_en_nicaragua.pdf

JARQUÍn CHAMORRO, Mateo. et al. 2020. Anhelos de un Nuevo Horizonte. Aportes para una Nicaragua Democrática. San José: FLACSO de Costa Rica. 
LARA BENAVIDEZ, Rebeca Saray. 2015. "Políticas públicas, sostenibilidad ambiental y desarrollo de Nicaragua». Revista Electrónica de Investigación en Ciencias Económicas de UNAN-Managua, 6: 158-17. Acceso el 7 de diciembre de 2019. https://www.revistasnicaragua.net.ni/index.php/reice/article/view/2011

LÓPEZ ZEPEDA, Leonardo Francisco. 2016. «La revolución y el desarrollo histórico del cooperativismo en Nicaragua». Revista Electrónica de Investigación en Ciencias Económicas, Departamento de Economía Agrícola, UNAN-Managua, 7: 216-228. https://revistacienciaseconomicas.unan.edu.ni/index. php/REICE/article/view/104

MÁRQUEZ, Gustavo. 2009. "¿Los de afuera?». En La lucha contra la exclusión social en América Latina: una mirada desde Europa. 181-195. La Paz: BID/ Eurosocial/Comisión Europea/Plural Editores.

MARTíNEZ RIVERA, Eddy. 2010. Derecho de la seguridad social. Managua: Universidad Centroamericana.

MORENO ARESO, Leyre. 2018. «Nicaragua: Situación del colectivo LGTBI». Comisión Española de Ayuda al Refugiado. https://boletinderechoshumanos. files.wordpress.com/2019/01/lgtb-nicaragua-2018.pdf

NAVARRO MEDAL, Karlos. 2018. "Repeal of the privatization of the pension system in Nicaragua, extension of social security», Reversing Pension Privatizations: Rebuilding public pension systems in Eastern Europe and Latin America, ILO, paper n. ${ }^{\circ}$ 70: 779-291.

- 2003. La Seguridad Social en Nicaragua: Antecedentes histórico-jurídicos. Managua: Bitecsa.

ORGANIZACIÓN INTERNACIONAL DEL TRABAJO. 2018. «Presente y futuro de la protección social en America Latina y el Caribe». Panorama Temático Laboral. Publicaciones: Oficina Regional para América Latina y el Caribe. Acceso el 14 de diciembre de 2019. https://www.ilo.org/americas/publicaciones/WCMS_633654/lang--es/index.htm

OTERO, Cirilo Antonio. 2017. «La exclusión social en Nicaragua». Opinión en el Diario La Prensa. Acceso el 2 de febrero. https://www.laprensa.com. ni/2017/05/23/opinion/2233769-exclusion-social-en-nicaragua

RUIZ GARCÍA, Alfredo y PELEGRÍN CRUZ, Emma. 2017. "Incidencias de la variabilidad y el cambio climático en la opción migratoria de familias habitantes de comunidades de los municipios de El Viejo, La Paz Centro, Ciudad Darío, Managua y Tola». Cuadernos de Investigación n. ${ }^{\circ} 31:$ 39-68.

SALOM ECHEVERRIA, Alberto et al. 1992. El estado del cooperativismo en Nicaragua. San José, Alianza Cooperativa Internacional.

SÁNCHEZ BOZA, Roxana. 2019. «El principio de autonomía e independencia. Consecuencias jurídicas y económicas derivadas de su aplicación en Costa Rica», en Boletín de la Asociación Internacional de Derecho Cooperativo, n. ${ }^{\circ}$ 55: 55-86. DOI: http://dx.doi.org/10.18543/baidc-55-2019pp55-86.

SÁNCHEZ-URÁN AZAÑA, Yolanda. 2005. «Excluidos sociales: Empleo y protección social», en Revista del Ministerio de Trabajo y Asuntos Sociales, n. ${ }^{\circ}$ 59: $171-190$. 
SERVICIO EUROPEO DE ACCIÓN EXTERIOR. 2014. «Documento de estrategia nacional y programa indicativo plurianual 2014-2020. Nicaragua». Acceso el 4 de enero 2020. https://eeas.europa.eu/sites/eeas/files/20150610_01_ es.pdf

SOTO ALEMÁN, Lien. 2017. «Notas en pos de la regulación jurídica del balance social cooperativo en Cuba», en Boletín de la Asociación Internacional de Derecho Cooperativo, n. ${ }^{\circ}$ 51: 317-344. DOI: http://dx.doi. org/10.18543/baidc-51-2017pp317-344.

VALLADARES CASTILLO, Francisco. 1996. Derecho cooperativo en Nicaragua. León: Universidad Nacional Autónoma de Nicaragua. 


\section{Derechos de autor}

El Boletín de la Asociación Internacional de Derecho Cooperativo es una revista de acceso abierto lo que significa que es de libre acceso en su integridad inmediatamente después de la publicación de cada número. Se permite su lectura, la búsqueda, descarga, distribución y reutilización legal en cualquier tipo de soporte sólo para fines no comerciales y según lo previsto por la ley; sin la previa autorización de la Editorial (Universidad de Deusto) o el autor, siempre que la obra original sea debidamente citada (número, año, páginas y DOI si procede) y cualquier cambio en el original esté claramente indicado.

\section{Copyright}

The International Association of Cooperative Law Journal is an Open Access journal which means that it is free for full and immediate access, reading, search, download, distribution, and lawful reuse in any medium only for non-commercial purposes, without prior permission from the Publisher or the author; provided the original work is properly cited and any changes to the original are clearly indicated. 